\title{
Clinical and familial profile of bipolar disorder with and without obsessive-compulsive disorder: an Indian study
}

\author{
Perfil clínico e familiar do transtorno bipolar com e sem \\ transtorno obsessivo-compulsivo: estudo indiano
}

\author{
Firoz Kazhungil, ${ }^{1}$ Ajitha Cholakottil,, ${ }^{2}$ Shihab Kattukulathil, ${ }^{2}$ Abdurazak Kottelassal, ${ }^{2}$ Rajeesh Vazhakalayil ${ }^{2}$
}

\begin{abstract}
Introduction: Comorbid obsessive-compulsive disorder (OCD) is common in bipolar disorder (BD). Clinical characteristics, functionality and familial pattern of this comorbidity are largely understudied.

Objective: To assess clinical profile, familial loading of psychiatric disorders and level of functioning in remitted BD patients who have comorbid OCD and to compare results with those of remitted BD patients without OCD.

Methods: Remitted BD-I subjects were assessed using the Structured Clinical Interview for DSM-IV Axis I Disorders, Global Assessment of Functioning Scale (GAF), Hamilton Depression Rating Scale (HDRS), Young Mania Rating Scale (YMRS), YaleBrown Obsessive-Compulsive Scale (Y-BOCS) and Family Interview for Genetic Studies (FIGS). BD patients with and without $O C D$ were compared. Group differences were analyzed using the chi-square test and the independent samples $t$ test. Values $<0.05$ were considered statistically significant.

Results: Of the 90 remitted BD-I patients, 35.5\% $(n=32)$ had obsessive-compulsive symptoms/OCD. The BD-OCD group showed significantly lower GAF scores, higher rates of suicidal attempts, hospitalizations, manic and depressive episodes compared to the group with BD only $(p<0.05)$. In addition, first and second-degree relatives had higher rates of $B D-O C D$ and $O C D$, but not of BD.

Conclusions: $B D-O C D$ is characterized by more severe $B D$, more dysfunction and higher familial loading of BD-OCD and OCD. Larger studies involving relatives of probands will help to confirm our findings and to delineate nosological status of BDOCD comorbidity.
\end{abstract}

Keywords: Bipolar disorder, comorbidity, familial loading, obsessive-compulsive disorder.

\section{Resumo}

Introdução: Transtorno obsessivo-compulsivo (TOC) comórbido é comum no transtorno bipolar (TB). Características clínicas, funcionalidade e história familiar dessa comorbidade são pouco estudadas.

Objetivo: Avaliar o perfil clínico, a carga familiar de transtornos psiquiátricos e o nível de funcionalidade em pacientes com TB em remissão que apresentam TOC comórbido e comparar os resultados com aqueles obtidos em pacientes com TB em remissão sem TOC.

Métodos: Indivíduos com TB-I em remissão foram avaliados usando a Entrevista Clínica Estruturada para o DSM-IV - Transtornos do Eixo I, Escala de Avaliação Global do Funcionamento, Escala de Depressão de Hamilton, Escala de Mania de Young, Escala Obsessivo-Compulsiva de Yale-Brown e Entrevista Familiar para Estudos Genéticos. Pacientes com TB com e sem TOC foram comparados. Diferenças entre os grupos foram analisadas usando o teste do qui-quadrado e o teste $t$ para amostras independentes. Valores $<0,05$ foram considerados estatisticamente significativos. Resultados: Dos 90 pacientes com TB-I em remissão, 35,5\% $(n=32)$ tinham sintomas obsessivo-compulsivos/TOC. O grupo com TB-TOC mostrou escores significativamente mais baixos na Escala de Avaliação Global do Funcionamento, maiores taxas de tentativas de suicídio, hospitalizações, episódios maníacos e depressivos quando comparado ao grupo com apenas TB $(p<0,05)$. Além disso, familiares de primeiro e segundo grau mostraram maiores níveis de TB-TOC e TOC, mas não de TB.

Conclusões: TB-TOC se caracteriza por TB de maior gravidade, mais disfunção e maior carga familiar de TB-TOC e TOC. Estudos maiores envolvendo familiares de probandos ajudarão a confirmar nossos achados e a delinear o status nosológico de TB-TOC comórbidos.

Descritores: Transtorno bipolar, comorbidade, carga familiar, transtorno obsessivo-compulsivo.

\footnotetext{
${ }^{1}$ Department of Psychiatry, Government Medical College, Kozhikode, Kerala, India. ${ }^{2}$ Department of Psychiatry, Government Medical College, Manjeri, Kerala, India. 


\section{Introduction}

Anxiety disorders are highly prevalent in bipolar disorder (BD), and obsessive-compulsive disorder (OCD) is one of the commonest anxiety disorders associated with BD. Population-based studies reported lifetime prevalence rates of comorbid BD-OCD ranging between 11.1 and $21 \% .^{1-3}$ The prevalence of OCD may be masked by presence of manic or depressive symptoms in $B D$, which is evident from data in remitted patients where the reported prevalence of comorbid OCD is quite high (35 to $38.6 \%$ ). ${ }^{4-6}$ In children with $\mathrm{BD}$, the prevalence of OCD ranges between 20.7 and $46.9 \% .^{7}$ The high prevalence of such association is even argued for a specific subtype of BD or OCD or one disorder increasing the propensity to develop the other.

Presence of OCD poses a huge impact on morbidity of patients with $\mathrm{BD}$. BD, when comorbid with $\mathrm{OCD}$, has been associated with greater disability and poorer quality of life,,$^{7,8}$ poor functioning $7,9,10$ and higher unemployment ${ }^{7,9}$ in comparison to 'pure' OCD or 'pure' $\mathrm{BD}$. It is also associated with episodic course, ${ }^{11}$ rapid cycling ${ }^{8}$ and more frequent hospitalizations. ${ }^{7}$ Comorbid OCD may increase mortality in BD as studies have consistently shown an increase of suicidal ideas and attempts among patients with BD-OCD.4,7,8,12 OCD in $B D$ is a poor prognostic factor too, as poor treatment response and polypharmacy are well documented in BD-OCD comorbidity. ${ }^{7,13-15}$

A recent large sample study from India showed that OCD is severe in BD-OCD. ${ }^{9}$ In another study, severity of $O C D$ in $B D$ was significantly higher when compared with pure $O C D$ and subjects had moderate to severe scores on the Y-BOCS severity scale. ${ }^{16}$ However, another study involving remitted bipolar-OCD patients showed that BD-OCD had less severe OCD compared to pure $O C D$, and that $O C D$ was mild to moderate on Y-BOCS in BD-OCD. ${ }^{6}$ Many studies reported that OCD in BD has an episodic course (similar to BD), with worsening in depression and improvement in manic phases. ${ }^{7}$ But a chronic course has been reported in two studies, ${ }^{9,17}$ and a recent study has documented worsening of OCD in manic phases. ${ }^{9} \mathrm{BD}-\mathrm{OCD}$ patients had a higher number of depressive episodes than patients with BD alone, which may be attributed to poor treatment of OCD in BD-OCD due to fear of causing mood instability. ${ }^{7,18}$ Only a few studies have analyzed $O C D$ in remitted BD. ${ }^{5,6}$ These studies found that OCD-BD subjects were characterized by episodic course of $O C D$, high familial loading for mood disorders, and comorbidity with depression, social phobia, and generalized anxiety disorder. They also had less severe OCD and a different symptom profile compared to non-bipolar OCD. 5,6
A few researchers even argue for a specific subtype of BD-OCD due to its high prevalence, clinical characteristics, disability and poor treatment response. ${ }^{19,20}$ Conversely, a recent systematic review denotes scarcity of studies exploring BD-OCD.7 Also, the nosological status of this comorbidity is less studied. ${ }^{21}$ Family studies can be used for a better neurobiological and hence nosological understanding of BD-OCD comorbidity.

The objective of this study was to study the sociodemographic profile, clinical features, familial loading of psychiatric disorders and level of functioning in remitted patients with $B D$ who have comorbid $O C D$, and to compare the results with those obtained for remitted $B D$ patients without $O C D$.

\section{Methods}

\section{Subjects}

The study was conducted from February to May 2017 and involved patients attending the outpatient clinic of the department of psychiatry of a tertiary-level teaching hospital. The study protocol was approved by the institutional ethics committee of Government Medical College, Manjeri. Remitted subjects with BD aged between 18 and 60 years who fulfilled criteria from the Diagnostic and Statistical Manual of Mental Disorders, 4th edition (DSM-IV) for BD were included in the study after providing written informed consent (obtained from patient and caregiver). Clinical remission of BD was established based on treatment records, information from the patient and caregivers, and on a score $<8$ on both the Hamilton Depression Rating Scale (HDRS) and the Young Mania Rating Scale (YMRS). Patients with schizophrenia, schizoaffective disorder, major depressive disorder, mental retardation, epilepsy, cerebrovascular accidents or sensory impairments were excluded.

\section{Assessments}

The investigators were qualified psychiatrists and they performed screening for eligibility and assessments independently. Sociodemographic and clinical variables were obtained from the medical records and from interviews with the subjects and their caregivers. Life charting of the course of BD and its relationship with OCD was completed for each patient based on the information available from all the sources.

The clinical status of patients was assessed using the Structured Clinical Interview for DSM-IV Axis I Disorders (SCID-I), HDRS, YMRS and the Yale-Brown ObsessiveCompulsive Scale (Y-BOCS). A total score $\geq 16$ on the Y-BOCS was required for a diagnosis of clinically significant $O C D$; patients showing a total score $<16$ on 
the Y-BOCS and not fulfilling DSM-IV criteria for OCD were labelled as having obsessive-compulsive symptoms (OCS). Level of functioning was assessed using the Global Assessment of Functioning Scale (GAF).

Family history of psychiatric illness was assessed using the Family Interview for Genetic Studies (FIGS). This instrument has been used to screen for psychiatric disorders in relatives of patients when direct assessment of the relatives is impossible. It was developed by the National Institute of Mental Health (NIMH), has been well validated and is widely used in psychiatric genetic studies. ${ }^{22}$ There are three steps to using the FIGS: 1 ) review the pedigree with the informant; 2 ) ask the general screening questions; and 3) complete a face sheet and symptom checklists with selected relatives. Family history of major psychiatric illnesses (psychosis, depression, mania, alcohol/substance abuse) can be determined using FIGS. As FIGS does not cover family history of OCD, we used questions in the OCD module of the SCID-I to assess family history of OCD.

\section{Statistical analysis}

Statistical analysis was performed using the Statistical Package for the Social Sciences (SPSS) version 15. Because the data were normally distributed, parametrical tests were used for analysis. The chi-square test was used to compare categorical variables; continuous variables were analyzed using the independent samples $t$ test. Values $<0.05$ were considered statistically significant.

\section{Results}

Of 127 patients screened, 90 were included in the study ( 8 patients were excluded due to diagnostic reasons, 14 patients did not fulfil remission criteria as stated above, 10 refused to participate, 3 presented mental retardation and 2 had epilepsy). Out of 90 remitted BD patients, 35.5\% $(n=32)$ had OCS/OCD. In the BD-OCD group, $37.5 \%(n=12$ of 32$)$ had OCS, and the remaining $62.5 \%(n=20)$ had OCD. Also, $25 \%(n=8)$ of the patients in the BD-OCD group had predominantly obsessions, $37.5 \%$ had predominantly compulsions $(n=12)$, and $37.5 \%(n=12)$ had mixed obsessions and compulsions. Age of onset of OCD in the BD-OCD group was $26.40 \pm 10.22$ years, and duration of OCD was $92.90 \pm 79.97$ months. Y-BOCS total scores, obsessions and compulsions subscale scores were 17.39 \pm 8.57 , $7.35 \pm 4.11$ and $9.81 \pm 5.21$, respectively.

There were no statistically significant differences in age $(39.36 \pm 11.24$ years vs. $41.03 \pm 11.77, t=-0.66$, $p=0.50)$, gender ( $64 \%$ men vs. $75 \%$ women, $X^{2}=1.18$, $p=0.27)$, marital status $\left(x^{2}=2.05, p=0.72\right)$, residential status ( 57 vs. $56 \%$ urban, $X^{2}=0.004, p=0.95$ ), occupation $\left(x^{2}=3.57, p=0.82\right)$ and years of education $(8.09 \pm 3.22$ vs. $9.00 \pm 4.11$ years, $x^{2}=-1.16, p=0.50$ ) between $B D$ patients with and without comorbid OCD (Table 1). With respect to clinical variables, there were no significant group differences in age of onset of $B D(24.74 \pm 8.39$ vs. $23.38 \pm 7.23$ years, $t=0.77, p=0.44)$, HDRS $(3.40 \pm 2.07$ vs. $3.25 \pm 1.93, t=0.33, \mathrm{p}=0.74)$ and YMRS $(2.26 \pm 1.88$ vs. $3.06 \pm 2.18, t=-1.83, \mathrm{p}=0.07)$. GAF scores were significantly lower in BD-OCD patients than in patients with BD only $(67.12 \pm 13.66$ vs. $58.74 \pm 15.94, t=2.60$, $\mathrm{p}=0.01$ ) (Table 2).

Comparing episode and illness characteristics, number of manic episodes ( $4.41 \pm 3.59$ vs. $6.22 \pm 4.07, X^{2}=-$ 2.17, $\mathrm{p}=0.03)$ and depressive episodes $(2.33 \pm 1.42 \mathrm{vs}$. $\left.3.16 \pm 2.02, x^{2}=-2.27, p=0.02\right)$ were significantly higher in the BD-OCD group, whereas number of mixed episodes $(1.33 \pm 0.99$ vs. $1.03 \pm 0.99, t=1.34, p=0.29)$ did not differ significantly. BD-OCD patients showed a significantly higher number of suicidal attempts $(0.29 \pm 0.59$ vs. $1.19 \pm 0.93, t=-5.56, \quad \mathrm{p}<0.001)$ and hospitalizations ( $2.71 \pm 2.26$ vs. $4.41 \pm 3.39, t=-2.84, p=0.01)$. Duration of manic episodes $(1.42 \pm 0.77$ vs. $1.68 \pm 0.70$ months, $t=-1.60, \mathrm{p}=0.11)$ and depressive episodes $(2.71 \pm 1.37$ vs. $3.00 \pm 1.44$ months, $t=-0.91, \mathrm{p}=0.36$ ) did not differ significantly between the two groups (Table 2). Number of failed trials of mood stabilizers $(1.17 \pm 0.46$ vs. $1.28 \pm 0.73, t=-0.87, \mathrm{p}=0.39)$, antipsychotics $(1.09 \pm 0.63$ vs. $1.19 \pm 0.59, t=-0.75, p=0.46)$ and antidepressants $(0.21 \pm 0.41$ vs. $0.28 \pm 0.46, t=-0.79, p=0.43)$ used in their lifetime did not differ between bipolar patients with and without OCD (Table 2).

When comparing the number of family members suffering from psychiatric disorders between the two groups, the BD-OCD group showed a significantly higher familial loading for OCD $(p=0.02)$ and BD-OCD $(p=0.01)$ when compared to the group with BD without $O C D$. Familial loading for $B D(p=0.49)$, depression $(p=0.37)$, mania $(p=0.21)$, psychosis $(p=0.09)$ and alcohol/drug use $(p=0.67)$ was not significantly different between the $B D-O C D$ and BD-only groups. Familial loading for $O C D$ or $\mathrm{BD}$ along with depression, psychosis and alcohol/ drug use disorder was not significant either (Table 2).

\section{Discussion}

The prevalence of OCS/OCD in our patients with remitted BD was $35.5 \%$. Only a few previous studies have looked into prevalence rates for OCD in remitted patients with BD. Tamam \& Ozpoyraz, in 2002, assessed 70 remitted patients with BD type 1 and found a 
prevalence of OCD of $39 \% .{ }^{5}$ Another more recent study from India involving 80 remitted bipolar outpatients also reported a prevalence of $35 \%$ for OCD. ${ }^{6}$ The prevalence rate found in our study is concordant with those previous studies. However, in population-based studies of adults with $\mathrm{BD}$, the proportion of patients with comorbid $\mathrm{OCD}$ ranges from 13 to $21 \%$, and in hospital-based studies, from 3 to $16 \% .^{7}$ This very lower prevalence rates compared to remitted $\mathrm{BD}$ can be due to underdiagnosis of OCS during active phases of BD. Phenomenological characterization of OCS during affective sates is difficult, unless in case of typical OCS, because there are chances of ruminations being labelled as depressive ruminations and repetitive behaviors as part of psychomotor activation. So, based on our results, we may suggest that exploring OCS in patients with $B D$ in remitted state would be ideal. A previous study involving patients with remitted $B D$ reported a female preponderance for $O C D$ in $\mathrm{BD},{ }^{5}$ whereas another study did not show any gender difference. ${ }^{6}$ There were no gender differences in the prevalence of OCD in our study either. Our group of BDOCD had higher Y-BOCS scores compared to another study of remitted patients. ${ }^{6}$
Our patients with BD-OCD showed a lower level of functioning on GAF compared to those with BD only. This is a very important factor for prognosis. Many other studies also denote poor functionality in BD-OCD patients. . $^{-10}$ Poor scores on GAF could be a product of a higher number of manic and depressive episodes in our $B D-O C D$ subjects, but there was no difference in the mean duration of manic or depressive episodes in relation to patients with BD alone. Number of hospitalizations was higher in our BD-OCD group, which also indicates a poor prognosis in BD-OCD when compared to either $B D$ or OCD alone. ${ }^{7}$ This finding has been reported consistently across many studies of BD-OCD. $7,15,16,23,24$ Our study found a higher number of suicidal attempts in BD-OCD. Many previous studies also report the same finding. $4,7,8,12$ However, a large sample study described that current suicide risk is not increased in BD-OCD compared to $\mathrm{BD} .{ }^{9}$ No other studies involving patients with $B D$ in remitted state have explored suicidal risk in BD-OCD in comparison to BD. We could not find a more rampant use of mood stabilizers, antipsychotics or antidepressants in the BD-OCD group, even though polypharmacy is very frequently reported in $B D-O C D$

Table 1 - Sociodemographic characteristics

\begin{tabular}{|c|c|c|c|c|}
\hline Variable & BD without OCD $(n=58)$ & BD with OCD $(n=32)$ & $t /$ chi square & $\mathbf{p}$ \\
\hline Age (years) & $39.36 \pm 11.24$ & $41.03 \pm 11.77$ & -0.66 & 0.50 \\
\hline Gender & & & 1.18 & 0.27 \\
\hline Male & $21(36)$ & $8(25)$ & & \\
\hline Female & $37(64)$ & $24(75)$ & & \\
\hline Marital status & & & 2.05 & 0.72 \\
\hline Single & $9(15)$ & $7(22)$ & & \\
\hline Married & $39(67)$ & $17(53)$ & & \\
\hline Separated & $4(7)$ & $4(11)$ & & \\
\hline Widowed & $1(2)$ & $1(3)$ & & \\
\hline Divorced & $5(9)$ & $3(9)$ & & \\
\hline Residence & & & 0.004 & 0.95 \\
\hline Rural & $25(43)$ & $14(44)$ & & \\
\hline Urban & $33(57)$ & $18(56)$ & & \\
\hline Education (years) & $8.09 \pm 3.22$ & $9.00 \pm 4.11$ & -1.16 & 0.50 \\
\hline Occupation & & & 3.57 & 0.82 \\
\hline Homemaker & $35(60)$ & $17(53)$ & & \\
\hline Laborer & $8(14)$ & $5(16)$ & & \\
\hline Unemployed & $4(7)$ & $2(6)$ & & \\
\hline Student & $3(5)$ & $3(9)$ & & \\
\hline Business & $2(3)$ & $3(9)$ & & \\
\hline Farmer & $3(5)$ & $1(3)$ & & \\
\hline Employer & $2(3)$ & $0(0)$ & & \\
\hline Retired & $1(2)$ & $1(3)$ & & \\
\hline
\end{tabular}

Data presented as mean \pm standard deviation and $\mathrm{n}(\%)$.

$\mathrm{OCD}=$ obsessive-compulsive disorder. 
studies. ${ }^{7,13-15}$ This is particularly important because depressive episodes are higher in BD-OCD, but there is no more use of antidepressants. A similar finding was reported by Shashidhara et al. in a large sample size study. ${ }^{9}$ But these findings are contrary to the results reported in the Systematic Treatment Enhancement Program for Bipolar Disorder (STEP-BD) study, in which BD patients with comorbid anxiety disorder were more likely to receive treatment with an antidepressant than BD patients without anxiety. ${ }^{12}$ The main reason for underprescription in our study may be fear of manic switches associated with antidepressant use. ${ }^{10}$

Most importantly, our study suggests that BD-OCD patients have more family history of $B D-O C D$ and $O C D$, triggering postulates that either BD-OCD may have its familial inheritance from $O C D$ or it may be a distinct entity with its own inheritance pattern. None of the previous studies of BD-OCD have investigated or reported familial transmission of BD-OCD combined. ${ }^{7} \mathrm{~A}$ few previous investigations have assessed family history of OCD or BD in BD-OCD. ${ }^{7,9,14,24-26}$ BD-OCD patients may have a higher prevalence of family history of mood disorders and a lower prevalence of family history of OCD in comparison with OCD patients, ${ }^{14,24,25}$ even though study found the reverse ${ }^{25}$ and another study found higher family history of OCD but not of BD. ${ }^{9}$ Yet another study found no significant differences in family history of $O C D$, depression or mania in patients with OCD with or without BD. ${ }^{10}$ Our study also failed to find any higher prevalence of $O C D, B D$, depression, mania or schizophrenia in patients with BD-OCD. A recent review has suggested that $B D-O C D$ may more closely resemble $B D$ rather than $O C D$, and rather than being a separate entity; however, the same review reported a major limitation of very small number of studies using structured assessment for familial loading of psychiatric

Table 2 - Clinical and familial characteristics

\begin{tabular}{|c|c|c|c|c|}
\hline Variable & $\begin{array}{l}\text { BD without OCD } \\
\text { (mean } \pm \text { SD) }\end{array}$ & $\begin{array}{l}\text { BD with OCD } \\
(\text { mean } \pm \text { SD) }\end{array}$ & $t$ value & $\mathbf{p}$ \\
\hline Age at onset of BD, years & $24.74 \pm 8.39$ & $23.38 \pm 7.23$ & 0.77 & 0.44 \\
\hline HDRS score & $3.40 \pm 2.07$ & $3.25 \pm 1.93$ & 0.33 & 0.74 \\
\hline YMRS score & $2.26 \pm 1.88$ & $3.06 \pm 2.18$ & -1.83 & 0.07 \\
\hline GAF score & $67.12 \pm 13.66$ & $58.74 \pm 15.94$ & 2.60 & 0.01 \\
\hline \multicolumn{5}{|l|}{ Number of episodes } \\
\hline Mania & $4.41 \pm 3.59$ & $6.22 \pm 4.07$ & -2.17 & 0.03 \\
\hline Depression & $2.33 \pm 1.42$ & $3.16 \pm 2.02$ & -2.27 & 0.02 \\
\hline Mixed & $1.33 \pm 0.99$ & $1.03 \pm 0.99$ & 1.34 & 0.29 \\
\hline Duration of manic episodes & $1.42 \pm 0.77$ & $1.68 \pm 0.70$ & -1.60 & 0.11 \\
\hline Duration of depressive episodes & $2.71 \pm 1.37$ & $3.00 \pm 1.44$ & -0.91 & 0.36 \\
\hline Number of suicidal attempts & $0.29 \pm 0.59$ & $1.19 \pm 0.93$ & -5.56 & $<0.001$ \\
\hline Number of hospitalizations & $2.71 \pm 2.26$ & $4.41 \pm 3.39$ & -2.84 & 0.01 \\
\hline Failed trials of mood stabilizers & $1.17 \pm 0.46$ & $1.28 \pm 0.73$ & -0.87 & 0.39 \\
\hline Failed trials of antipsychotics & $1.09 \pm 0.63$ & $1.19 \pm 0.59$ & -0.75 & 0.46 \\
\hline Failed trials of antidepressants & $0.21 \pm 0.41$ & $0.28 \pm 0.46$ & -0.79 & 0.43 \\
\hline Familial loading of psychiatric disorders & \multicolumn{2}{|c|}{ Number of affected members ( $n$ ) } & $t$ & $\mathbf{p}$ \\
\hline BD & 14 & 8 & -0.68 & 0.49 \\
\hline OCD & 3 & 7 & -2.21 & 0.02 \\
\hline Depression & 4 & 4 & -0.88 & 0.37 \\
\hline Mania & 3 & 4 & -1.23 & 0.21 \\
\hline Psychosis & 6 & 8 & -1.70 & 0.09 \\
\hline$B D+O C D$ & 3 & 6 & -2.46 & 0.01 \\
\hline OCD + psychosis & 2 & 1 & 0.08 & 0.93 \\
\hline BD + alcohol/drug use & 2 & 3 & -0.97 & 0.33 \\
\hline OCD + alcohol/drug use & 0 & 0 & - & - \\
\hline
\end{tabular}

$\mathrm{BD}=$ bipolar disorder; GAF = Global Assessment of Functioning Scale; HDRS = Hamilton Depression Rating Scale; OCD = obsessive-compulsive disorder; SD = standard deviation; YMRS = Young Mania Rating Scale. 
disorder.7 Our study goes against those findings; we postulate that BD-OCD may be a separate entity as per our study.

The strengths of our study include having been done in remitted patients, to avoid effect of mood status on assessments, and use of structured assessments. Limitations of this study include a small sample size and non-availability of a data recording system. We did not analyze the phenomenology and course of OCD in BD as we did not have an OCD group for comparison.

\section{Conclusions}

BD-OCD is associated with poorer functioning, more manic and depressive episodes, more suicidal attempts and a higher number of hospitalizations compared to $B D$ without comorbid OCD. High familial loading of OCD and BD-OCD, but not of BD, was found in our study. Our findings may indicate the existence of a separate entity, 'bipolar OCD', or may suggest that presence of OCD in relatives increases the risk for $B D-O C D$. Large sample sized follow-up studies focusing on family analysis of siblings and offspring of patients with BD-OCD will help us better understand this entity.

\section{Disclosure}

No conflicts of interest declared concerning the publication of this article.

\section{References}

1. Chen YW, Dilsaver SC. Comorbidity for obsessive-compulsive disorder in bipolar and unipolar disorders. Psychiatry Res. 1995;59:57-64.

2. Faravelli C, Abrardi L, Bartolozzi D, Cecchi C, Cosci F, D'Adamo $D$, et al. The Sesto Fiorentino study: background, methods and preliminary results. Lifetime prevalence of psychiatric disorders in an Italian community sample using clinical interviewers. Psychother Psychosom. 2004;73:216-25.

3. Merikangas KR, Akiskal HS, Angst J, Greenberg PE, Hirschfeld RM, Petukhova $M$, et al. Lifetime and 12-month prevalence of bipolar spectrum disorder in the National Comorbidity Survey replication. Arch Gen Psychiatr. 2007:64:543-52.

4. Kruger S, Braunig P, Cooke RG. Comorbidity of obsessivecompulsive disorder in recovered inpatients with bipolar disorder. Bipolar Disord. 2000;2:71-4.

5. Tamam L, Ozpoyraz N. Comorbidity of anxiety disorder among patients with bipolar I disorder in remission. Psychopathology. 2002; 35:203-9.

6. Zutshi A, Reddy YC, Thennarasu K, Chandrashekhar CR. Comorbidity of anxiety disorders in patients with remitted bipolar disorder. Eur Arch Psychiatry. Clin Neurosci. 2006;256:428-36.

7. Amerio A, Odone A, Liapis CC, Ghaemi SN. Diagnostic validity of comorbid bipolar disorder and obsessive-compulsive disorder: a systematic review. Acta Psychiatr Scand. 2014;129:343-58.
8. Magalhaes PV, Kapczinski NS, Kapczinski F. Correlates and impact of obsessive-compulsive comorbidity in bipolar disorder. Compr Psychiatry. $2010 ; 51: 353-6$.

9. Shashidhara M, Sushma BR, Viswanath B, Math SB, Janardhan Reddy YC. Comorbid obsessive compulsive disorder in patients with bipolar-I disorder. J Affect Disord. 2015;174:367-71.

10. Angst J, Gamma A, Endrass J, Hantouche E, Goodwin R, Ajdacic $\mathrm{V}$, et al. Obsessive-compulsive syndromes and disorders: significance of comorbidity with bipolar and anxiety syndromes. Eur Arch Psychiatry Clin Neurosci. 2005;255:65-71.

11. Strakowski SM, Sax KW, McElroy SL, Keck PE Jr, Hawkins JM, West SA. Course of psychiatric and substance abuse syndromes co-occurring with bipolar disorder after a first psychiatric hospitalization. J Clin Psychiatry. 1998;59:465-71.

12. Simon NM, Otto MW, Wisniewski SR, Fossey M, Sagduyu K, Frank $\mathrm{E}$, et al. Anxiety disorder comorbidity in bipolar disorder patients: data from the first 500 participants in the Systematic Treatment Enhancement Program for Bipolar Disorder (STEP-BD). Am J Psychiatry. 2004;161:2222-9.

13. Henry C, Van den Bulke D, Bellivier F, Etain B, Rouillon F, Leboyer M. Anxiety disorders in 318 bipolar patients: prevalence and impact on illness severity and response to mood stabilizer. J Clin Psychiatry. 2003;64:331-5.

14. Perugi G, Toni C, Frare F, Travierso MC, Hantouche E, Akiskal HS. Obsessive-compulsive-bipolar comorbidity: a systematic exploration of clinical features and treatment outcome. J Clin Psychiatry. 2002;63:1129-34.

15. Masi G, Millepiedi S, Perugi G, Pfanner C, Berloffa S, Pari C, Mucci M. Pharmacotherapy in paediatric obsessive-compulsive disorder: a naturalistic, retrospective study. CNS Drugs. 2009;23:241-52.

16. Timpano KR, Rubenstein LM, Murphy DL. Phenomenological features and clinical impact of affective disorders in OCD: a focus on the bipolar disorder and OCD connection. Depress Anxiety. 2012;29:226-33.

17. Perugi G, Akiskal HS, Gemignani A, Pfanner C, Presta S, Milanfranchi $A$, et al. Episodic course in obsessive-compulsive disorder. Eur Arch Psychiatry Clin Neurosci. 1998;248:240-44.

18. Issler CK, Amaral JA, Tamada RS, Schwartzmann AM, Shavitt RG, Miguel EC, et al.L. Clinical expression of obsessive-compulsive disorder in women with bipolar disorder. Rev Bras Psiquiatr. 2005;27:139-42.

19. Amerio A, Tonna M, Odone A, Ghaemi SN. Comorbid bipolar disorder and obsessive-compulsive disorder: an old debate renewed. Psychiatry Investig. 2016;13:370-71.

20. Amerio A, Tonna M, Odone A, Stubbs B, Ghaemi SN. Heredity in comorbid bipolar disorder and obsessive-compulsive disorder patients. Shanghai Arch Psychiatry. 2015;27:307-10.

21. Amerio A, Stubbs B, Odone A, Tonna M, Marchesi C, Ghaemi SN. The prevalence and predictors of comorbid bipolar disorder and obsessive-compulsive disorder: a systematic review and metaanalysis. J Affect Disord. 2015;186:99-109.

22. Maxwell E. The family interview for genetic studies manual (Intramural Research Program, Clinical Neurogenetics Branch). Washington: National Institute of Mental Health; 1992.

23. Joshi G, Mick E, Wozniak J, Geller D, Park J, Strauss S, et al. Impact of obsessive-compulsive disorder on the antimanic response to olanzapine therapy in youth with bipolar disorder. Bipolar Disord. 2010;12:196-204.

24. Mahasuar R, Janardhan Reddy YC, Math SB. Obsessivecompulsive disorder with and without bipolar disorder. Psychiatry Clin Neurosci. 2011;65:423-33.

25. Koyuncu A, Tukel R, Ozyildirim I, Meteris $H$, Yazici O. Impact of obsessive-compulsive disorder comorbidity on the sociodemographic and clinical features of patients with bipolar disorder. Compr Psychiatry. 2010;51:293-7.

26. Zutshi A, Kamath p, Reddy YC. Bipolar and nonbipolar obsessivecompulsive disorder: a clinical exploration. Compr Psychiatry. 2007;48:245-51.

\section{Correspondence:}

Ajitha Cholakottil

Department of Psychiatry, Government Medical College, Manjeri

Postal code 676121 - Kerala - India

Tel.: +918075912585

E-mail: drajithac@gmail.com 